\title{
Syntactic diacrisis in a rigid and a free word order language
}

\author{
Tadeusz Zabrocki \\ SPOŁECZNA AKADEMIA NAUK, UL ŁUCKA 11, 00-842 WARSZAWA \\ zabrocki.tadeusz@gmail.com
}

\begin{abstract}
The paper is concerned with some syntactic consequences of Polish being a synthetic language with a rich system of case inflections and English lacking morphological case (or having a residual form of it). It will be argued that this typologically significant grammatical difference provides an essential premise in a unified explanation for the clustering of a number of syntactic differences between the two languages.

The argument is based on a set of functionally motivated constraints on grammatical representations. The constraints are proposed as a part of a theory of "syntactic diacrisis" and are claimed to result from a) the general nature of language as a semiotic system, and b) the specific properties of the human parsing mechanism.

The paper consists of three sections. The first contains a brief discussion of the role and place of functional explanations in syntax and introduces the concept of a "parser's requirement on structure" (PROS).

The second section introduces and justifies some basic principles of "syntactic diacrisis".

The third focuses on several syntactic differences between English and Polish and shows how they could all be explained by reference to the interplay of the functional (theory of diacrisis)and grammatical factors.
\end{abstract}

\section{Functional requirements on structure}

The question whether the design of language is primarily determined by its use in communication, i.e. by its function, or by formal-grammatical (ultimately biological) factors, has emerged as one of the central points of contention in modern linguistics. Many linguists of the "functionalist" persuasion take the former position, rejecting the "autonomy of grammar" and attempting to deduce formal properties of grammar from their 
semantic and pragmatic functions. (cf. the discussion in Nemeyer 1998, Croft 1995).This has been challenged on several occasions by Chomsky, according to whom the claim that language is designed and/or evolved for communication is "radically false" (Chomsky 2007). For Chomsky, communication is only an "ancillary" factor that has some role in what he calls "language maintenance" and "the historical language change" (J. J. Bolhuis, N. Chomsky et al. 2014).

We will neither follow the extreme functionalists' rejection of formalgrammatical explanations, nor will we share Chomsky's extreme skepticism about the influence of the communicative function of language on its grammatical system. We will accept the autonomy of grammar as a distinct mental faculty with a significant biological underpinning. However, the actual shape of the grammatical competence will be conceived as the result of a variety of factors, several of which originate in the communicative purpose of language. The grammar of a language is taken to result from a compromise between what is biologically determined and what is communicatively useful. ${ }^{1}$ It seems premature to make sweeping claims about the relative significance of these factors before more is known about the influence on language design of systems and constraints other than principles of the Universal Grammar.

In what follows we will be concerned with some such factors and constraints which, unlike UG principles, are not linked to what Fodor calls "innate peculiarities of the grammar representation centers of the brain" but are closely related to the "externalization" of language as a semiotic system where messages are being encoded in formal representations in a way that makes it possible for the receiver (the hearer) to decode it in accordance with the intention of the sender (the speaker).

Natural languages are remarkably efficient communication tools in two related but conceptually distinct respects. First, the intended meanings are encoded in away that allows decoding with little distortion or confusion. Secondly the whole process of coding and decoding proceeds with the remarkable speed and ease, which seems as mysterious as the speed and

\footnotetext{
${ }^{1}$ Cf. the Negotiation Model of Fodor (1984), where what is described as a "compromise" is an effect of the "negotiations" and "trade-offs" between various external requirements on grammars. These are related to the necessity of language being mentally "representable, learnable, speakable (or externalizable through some other modality of expression (TZ)), understandable, and communicatively useful" (Fodor 1984:9).

2 This does not contradict Chomsky's idea that even before the "externalization", when the syntactic "nucleus" of language (the operation of Merge) has emerged as a mutation in the brain of some individual humanoid creature, it gave a considerable survival advantage to its carrier in terms of an increase of his "power of thought" in such aspects as reasoning and planning. The conjecture is that this communication-independent "survival" advantage of an individual, although it can account for the initial spreading of the language gene, is not sufficient to explain the subsequent enormous success of the species, which could only be attributed to the effectiveness of language as a communication tool.

3 See Kayne 1994, where the specific hierarchy/linear ordering link is argued to be universal.
} 
ease with which languages are acquired. The first property (the en/decoding effectiveness) implies that language is a well-designed semiotic system with a regular correspondence between the content and the physical form of signs. The second property (en/decoding efficiency) implies that the form of language signs is well suited to the biologically determined limitations of human articulation, perception and processing mechanisms. It is these two properties of linguistic communication which allow effective sharing of knowledge and experience among humans as well as precise planning and coordination of common actions. This in turn appears to be an extremely important if not decisive factor contributing to the evolutionary success of the human species. ${ }^{2}$

It should be expected that this remarkable adjustment to the demands of communicative effectiveness has left its mark on the grammatical system.

In the case of the first property (transparent meaning-form links) we can adduce trivial examples like different concepts coming under the guise of different sequences of speech sounds or different semantic functions of arguments like Agents or Patient being linked to different syntactic functions that in turn are tied to a different string position of arguments or different case endings. The semantically relevant relations that are behind the hierarchical syntactic structure (argument-predicate, head-modifier) are linked to linear ordering in a systematic way, in the non-inflectional languages like English at least. 3

The second property (speed and ease of language performance) should in a natural way lead to a set of conditions that the expressions of a natural language ought to meet in order to be spoken and understood the way they are, effortlessly and quickly. In Chomsky's terms, such conditions would constitute requirements that the sensory/motor systems, which take care of sentence production and parsing, impose on the grammatical representations that they interface with.

While the demands of the motor/production system will probably be restricted to phonology, several specific proposals have been made as to ways in which requirements of parsing might influence morphological and syntactic structure. The degree and significance of parsers' influence remain a matter of dispute, but its existence is unquestionable and the ongoing research based on cross-linguistic, typological evidence shows it to be much greater than expected.

While early research in the 1970s and1980's has focused on the parsing explanations for certain, relatively minor, grammatical facts like peculiar surface structure constraints on the deletion of complementizers (Chomsky and Lasnik1971) and relative pronouns (Bever and Langendoen 1971), the8os and 9os have brought attempts to account in parsing terms for some major syntactic phenomena, like Subjacency (Berwick and Weinberg 1984) or Greenberg's implicational word order universals (Hawkins 1983, 1994). A set of precisely formulated conditions, like Nested Dependency Constraint (NDC) (Fodor 1978) or Early Immediate Constituents (Hawkins 1994), were 
formulated, which described the expectations that the grammatical structures should fulfill if their processing was to proceed in an efficient, quick, effortless manner. Let us call such conditions PROS (Parser's Requirements on Structure).

PROS have to be distinguished from the grammatical properties that are motivated by them. A good example could be Hawkins's Early Immediate Constituents principle (EIC) mentioned above:

\section{1. "The human parser prefers linear orders that maximize the IC-to- non-IC ratios of constituent recognition domains (CRD)" (Hawkins 1994:77)}

The principle, supplemented with precise definitions of the concepts like "IC-to-non IC ratio", "CRD", and a method of the calculation of nonoptimal ratios, provides a unified functional explanation for a strong preference for those syntactic configurations which maximize the speed of recognition of the basic elements of phrase structure by the parser. This covers a wide range of syntactic facts from Greenberg's implicational word order universals to the Heavy NP Shift in English.

How can we know that a constraint such as EIC expresses the parser's preference and is not some sort of a grammatical output constraint? Why could the words "human parser prefers" not be replaced by "UG requires"? Ideally, in order to establish the link to parsing we should be able to deduce PROS from some psychologically real (not just formal) theory of parsing. Such a theory should provide a precise reconstruction of operations involved in the parsing of specific types of constructions, show which cognitive capacities are involved and what is the link between various aspects of structure and the amount of cognitive resources required to process them. Such a theory is, unfortunately currently not available. ${ }^{4}$

Fortunately, we can derive support for the "processing-related" character of a PROS from the same kind of evidence which has been routinely used to

\footnotetext{
${ }^{4}$ It is evident that the theoretical understanding of performance systems lags behind that of grammatical structure. The main reason for this is probably the different nature of data required to confirm theoretical claims. Grammatical theory relies on the abundance of easily accessible introspective well-formedness intuitions, the database for a theory of performance should come largely from psychological experiments, which leads to problems with experiment design and the interpretation of results.

It might also be that there is no separate language processing module in the human mind/brain which could constitute an object for such a theory. It might be that processing in general and parsing involves several different non-language specific cognitive domains and resources. Some indirect support for this last claim seems to come from research on the neural basis of processing. Newman et al. (2010) found out in a series of neuroimagining experiments that processing constructions in a language like English that "typically conveys grammatical information.... using word order" (positional languages in our terminology) activated "left-lateralized areas involved in working memory and lexical access" while "inflectional morphology sentences activated areas involved in building and analyzing combinatorial structure". These seem to be non-language specific cognitive capacities (excluding perhaps "lexical access").
} 
justify the UG status of conditions like Subjacency, ECP, EPP, etc. The evidence comes from the form of the conditions and the nature of the confirming evidence for them, i.e. the type of predictions they make. The violation of UG conditions (with their parameters fixed), like that of any language-specific grammatical rules, leads to "absolute" ill-formedness that cannot be alleviated with different lexical choice or disambiguating pragmatic context. Furthermore, the syntactic principles are formulated in a way that does not make reference to surface morphological idiosyncrasies brought about by morphophonological rules ( cf. discussion of the "garden path" sentences like "the horse raced past the barn fell" in Chomsky and Lasik 1971). Finally, the grammatical principles are not statements of preferences or tendencies, the requirements which they impose on structures are not quantified or graded (e. g. when the condition expresses a "preference for maximization/minimization").

In view of this, consider the predictions made by EIC, mentioned above. It is a statement about preference. The preferred word order patters ( $\mathrm{V}-\mathrm{O}$ and $\mathrm{P}-\mathrm{NP}$ in right-branching languages) have been grammaticalized, i.e. grammars have responded to parsers' pressure with grammatical rules which generate the word order configurations predicted by the preference. In this respect the evidence is no different in character from that evoked for the UG principle (Head Parameter) involved in a formal grammatical explanation for the same facts - a set of ungrammatical sentences like *John sent a letter Bill to. EIC, however, also makes predictions of a different type. For example, it predicts that in right-branching languages, "heavy" (complex) direct object NPs tend to be shifted to the end of the VP (by what used to be called the Heavy NP Shift rule):

2. a. ?? Bill met [the girl whom he used to date when he was a student at the Academy of Social Sciences] at the party.

b. Bill met at the party [the girl whom he used to date when he was a student at the Academy of Social Sciences].

2.a., in which the "heavy" direct object has not been shifted, is considered stylistically awkward and more difficult to understand, where the degree of difficulty is evidently related to the degree of "heaviness/complexity" of the object NP. The unacceptability of 2.a. is thus not due to its ungrammaticality (apparently, it could not have been grammaticalized for some, possibly grammar internal, reasons). Consequently, the principle which predicts the acceptability difference between 2.a. and 2.b. is not a grammatical principle/rule but rather a parser's preference that 2.a. does not fulfill.

A PROS type of conditions may thus influence language in two ways: a) an indirect way, when itis grammaticalized, i.e. when it motivates a grammatical condition, b) directly, when it manifests itself in(gradable) acceptability judgments and "stylistic" preferences, favoring some grammatical constructions over others. Moreover, this preference is stronger in situations when correct (i.e. as intended by the speaker) 
parsing must rely on grammatical clues only. If non-syntactic clues (semantic/or pragmatic) are present, the construction which violates PROS could be perfectly acceptable. Consider the sentence in 3. (discussed in Fodor 1984):

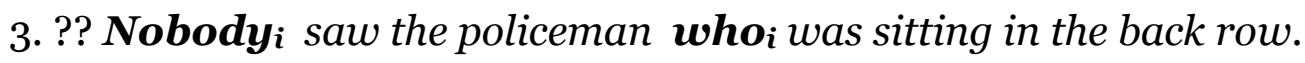

Sentence in 3. is unacceptable under the intended interpretation. This might be due to a PROS such as:

4. Avoid extraposition from the subject if the main verb of the clause is followed by an NP object.

The PROS in 4. could in turn be a consequence of the hypothesized parsing strategy which assumes "local structural associations between neighboring words" proposed in Frazier and Fodor (1978).

Consider now 5., which is much better than 3. Both sentences differ with respect to the lexical choice, which for pragmatic reasons forces the required interpretation, solving the problem for the syntactic parser:

5. Nobodyi saw the fistfight whoi was sitting in the back row.

\section{Syntactic diacrisis}

Let us consider a popular functional explanation for grammatical facts. It is well known that synthetic languages (e.g. Russian, Polish, Hungarian, Turkish) with their rich system of nominal case inflections (morphological case) show considerable freedom in the way their subjects and objects are positioned with respect to the verb and to each other. Generative approaches have traditionally accounted for this phenomenon of "free word order" ${ }^{5}$ with a special "scrambling" rule, which destroys the underlying order (uniformly SVO in some recent accounts). In languages like English, with only residual case inflections, this morphological property correlates with the syntactic property of a "rigid" word order such as the English SVO. The class of exceptions to the basic order is limited by the set of precisely defined restrictions on dislocations (Move in a GB or Internal Merge in a Minimalist framework).This correlation is easy to

\footnotetext{
5 "Free word order" languages have to be distinguished from languages with "no preferred /basic order". For example, it is well known that Polish and Russian show preference for SVO (this is the predominant interpretation of NP V NP structures with ACC/NOM syncretism (cf Polish "dziecko widzi prosię" ("child sees piglet")) The preference may have something to do with information flow iconicity. The point is that none of the possible combinations (SVO, SOV, VSO, VOS, OVS , OSV) are ruled out as ungrammatical. Cf. Dryer's distinction (Dryer 2013) between "flexible order languages" and languages "lacking dominant word order", the latter being a subset of the former.
} 
Tadeusz Zabrocki: Syntactic diacrisis in arigid and a free word order language

observe and widespread. It could be defined through two implicational universals:

6. a. If no/(or only residual) morphological case then no scrambling. b. If morphological case then (possible) scrambling.

In other words, free word order presupposes morphological case. The standard explanation of this correlation is not "grammar internal" or "formal" but functional. It has been summarized in the following way in Müller 2000

\section{7."A proper interpretation of sentences requires an unambiguous identification of the grammatical function of an argument NP. The grammatical function of an NP can be encoded by morphological Case or by assigning it an invariant structural position. If the first option is available, an argument NP does not have to occupy a fixed position in order for its grammatical function to be identified; however, if there is no morphological Case, a language must resort to an invariant position to ensure that an identification of the grammatical function of an NP is possible." (Müller 2000: 1)}

This informal account presupposes a general theoretical principle, a necessary element of the explanans in the deductive explanation. One has to assume that there is a strong functional pressure to avoid global ambiguity and the resulting strong preference for unique content-form pairings. This in turn does not follow from any innate grammatical principle but relates to some general assumptions in a general theory of language (not of grammar) such as: ${ }^{6}$

8. a. Language, apart from its psycho-biological basis, is a semiotic system employed in inter-human communication with the aim to facilitate human interaction and co-operation.

b. Such purpose-oriented systems have a property of homeostasis that allows them to maintain stable conditions necessary for the fulfillment of their purpose. In case of language, such "maintenance" involves keeping the amount of global ambiguity at a tolerable level.

There is a clear connection between 8. and the requirement of an "unambiguous identification of the grammatical function of an argument NP”. Given 8. and some additional assumptions (e.g. about the available

\footnotetext{
${ }^{6}$ In their role as "factors of language design" they are comparable to the "channeling" laws that Chomsky refers to in his recent writings (cf. Chomsky (2005)) They are "laws of nature" (like laws of computing efficiency), which are independent of the idiosyncrasies of the biology of the human brain but which channel and constrain language structure and development.
} 
means of formal identification), we can infer the statement "if there is no morphological Case a language must resort to an invariant position...." In simple terms, it "must" because it would be of little use otherwise.

Even though the link between 8. and 7. is evident, one would like to be able to explicate the terms like "unambiguous/unique identification" and "invariant position" within some "lower level" theory, less general and more precise. In what follows we would like to ground these concepts within the framework of the theory of linguistic "diacrisis", understood as the way of distinguishing/differentiating linguistic units from one another. The term "diacrisis" was first used in this sense by L. Zabrocki in his theory of "distinctive morphology" (Zabrocki 1962). The theory of diacrisis ("diacritology") in phonology and morphology was further developed in the writings of F. Grucza (Grucza 1970, 2010). Applied to syntax, it would refer to ways in which constituents and the relations between them (their functions) are differentiated from one another in their observable form.

The general motivation for "diacrisis" in natural languages comes from the above described tendency, characteristic of semiotic systems, to avoid global ambiguity. One of the principal ways in which it is realized is to preserve relevant distinctions necessary for the mapping of semantic content into grammatical/lexical form. The specific form of diacrisis, however, depends on the available formal diacritic devices (string position, morphology, intonation etc.), which might be a matter of historical accident, and on the requirements of the human parsing system, which should be able to effectively and efficiently "take notice" of the distinctions needed to decode the content. The requirements, to be expressed in the form of PROS types of constraints, are of a biolinguistic nature hence universal. This will be the case of the Unique Structural Identification Requirement (USIR), which will be proposed as the first principle of syntactic diacrisis:

\section{Unique Structural Identification Requirement (USIR)}

i) At the surface level (SL) each non-adjunct NP has a Diacritic Function (DF) that is unique within the thetadomain (clause (CP) or NP) of the NP.

ii) Each DF is uniquely (within its theta-domain) definable by reference to the non-lexical "perceivable" diacritic properties of $S L$.

By the surface level (SL) we will understand the level of grammatical representation that interfaces with the parsing system. It is close to what Chomsky calls PR, i.e. a string of sounds, but enriched with some non-audible but perceptually salient elements like some constituent boundaries (word, phrasal and clausal ) and categories. ${ }^{7}$ By Diacritic Function (DF) we will

\footnotetext{
${ }^{7}$ It is possible that the level of representation at which USIR applies has no counterpart in grammar, a computational algorithm linking PR and SR, but involves a mental
} 
understand a certain "role" or "position" in structure which is definable by reference to some non-lexical surface level diacritic property or a bundle of such properties. The concept is linked to, but different from, the traditional syntactic NP functions (Subject, Direct Object, etc.). The relationship between the two is to some extent analogous to that between morpheme (syntactic function) and a morph (DF) or between abstract and morphological case. Each syntactic function, an abstract entity, is "realized" through a corresponding DF. The concept of a DF is not limited to phrases in argument positions but is also applicable to pre-subject topics or fronted wh-phrases in questions. A set of DFs for the PR level will be defined for each language (or language type). ${ }^{8}$

USIR is not a grammatical principle but a functional requirement on structure linked to both factors behind syntactic "diacrisis" - semiotic and parsing related. On examples from English and Polish we will try to show that it motivates several strictly grammatical properties and has a role in a functional explanation of certain clusterings of these properties in both these languages. The peculiar status of USIR as a condition that mediates between grammar and the parser is illustrated by the diagram in 10 .



To find evidence for USIR let us first consider argument NPs (excluding pleonastic elements of various types) in theta positions. For these elements, it is not difficult to show that each of them must have a different syntactic function (and consequently DF), i.e. that 11. holds:

11. Each argument in a theta position has a distinct/unique syntactic function (and consequently, a distinct/unique DF).

representation of a sentence that has been built by the parser at some initial stage at which constituent boundaries and classes are being recognized but theta roles not yet assigned directly (by theta role assignment rules) or indirectly (through filler-gap links).

${ }^{8}$ This is similar to the standard approach to syntactic function in generative syntax where NP function are defined by their position in constituent structure (CF) configuration (e.g Subject of a sentence $=$ IP specifier $=$ an NP daughter of IP). This leads to a host of functions (e.g. Specifier in CP) which go beyond traditional functional terminology. The difference is that DFs of NPs are definable not through their position in the CS configuration but through string position and morphology. 
11. follows from Chomsky's theta criterion in 12. and a reasonable assumption about the theta role assignment in 13 .

\section{Theta Criterion:}

Each argument bears one and only one $\theta$-role, and each $\theta$-role is assigned to one and only one argument. (Chomsky 1981,p. 35)

13. Each theta role is assigned to an argument with a different syntactic function.

The sentences in 14. illustrate the way English and Polish conform to 11 .

14 a. [ John ] sent [ an invitation] to [ Mary ].

b. [ Janek ] wystat [ zaproszenie ] [ Marysi ].

Each of the three NPs has a different syntactic function (subject/specifier of IP - John/Janek, direct object/complement of the verb sent/wystat Marysi, object/complement of the preposition to - Mary, the dative (indirect) object of the verb Marysi). Each of these functions is realized as a different DF (subject precedes the verb, object of the verb follows and is adjacent to the verb, object of a preposition follows and is adjacent to the preposition).

The grammatical principle in 11. is related to USIR's semiotic motivation. It shows how arguments in theta positions fulfill the basic requirement of 9.i) by having distinct/unique DFs. This allows them to be linked to unique theta-roles as 12. demands. However, USIR requires more than that. First, it has a wider scope, applying also to non-arguments and to non-theta positions. The extension of USIR to non-arguments finds confirmation in empirical evidence. The distribution of non-arguments like the English existential there or the expletive it conforms to 9.i). They are either subjects (15.a.) or direct objects (13.b.) in ACI constructions (or subjects of infinitives depending of the analysis). They are never "loose" constituents outside a functional framework of a clause as in 16.

15. a. It is clear that John is guilty.

There is a man in a garden.

b. I want it to seem that John is guilty.

I expect there to be peace on earth.

16. * I there expect peace to be on earth

* I want to be it clear that John is guilty.

While the applicability of USIR to arguments can be explained with reference to the semiotic motivation for the constraint only (fundamental semantic distinctions should be reflected in the formal distinctions in a non-ambiguous and systematic way), the generalization of the constraint to $15 .-16$. will be assumed to be related to the demands of 
the processor. It is conceivable that (apart from the strictly grammatical reasons) the structures in 16 . would have caused problems for the parser. One way to substantiate this claim would be to restrict USIR to these NPs and CPs which are referred to by processing operations that affect phrases occupying specific positions in the structure of a sentence. It is these positions that we claim to require to be definable as unique DFs. The operations assigning theta roles to arguments in theta positions are a special case of these. Other examples are constructions where the parser must establish the link between co-indexed or co-superscripted elements. These comprise, among others, anaphor-antecedent constructions and structures with expletives as in 15.-16. It reasonable to assume that the parser has to establish a link between the "expletive" and its "associate" argument phrase as a precondition for a proper assignment of a theta role to the latter. The assignment of a theta role to "that John is guilty" and "a man" in 15. involves locating an expletive element in the grammatical subject position, which in turn requires that the subject be definable as a unique DF. Apparently, this is a precondition for its fast, efficient identification in the string of elements forming the PR interface.

USIR not only applies to both argument and non-argument but it also demands that the functions are definable in unique way in terms of the properties of the SL. This is a restrictive condition which eliminates a host of imaginable properties "invisible" at the SL such as indices of various sorts, non-phonological syntactic features on lexical items (e.g. abstract syntactic Case etc). This leaves such properties as string ordering, inflectional endings and major constituent boundaries such as CP, IP, $\mathrm{DP}(\mathrm{NP})$ and word boundaries.

It is an empirical question which constituent boundaries are to be considered as being accessible at SL interface. At present, we shall tentatively assume CP and IP boundaries as being "visible" at SL. We will exclude non-maximal projections. This is at present just a tentative assumption.

The examples in the table in 17. demonstrate that unique identifications for major NP syntactic functions are possible in both English and Polish.

17.

\begin{tabular}{|l|l|l|}
\hline \multicolumn{1}{|c|}{ English } & \multicolumn{1}{c|}{ Polish } \\
\hline $\begin{array}{l}\text { NP Subject of a } \\
\text { clause }\end{array}$ & $\begin{array}{l}\text { Precedes V } \\
\text { John likes Mary. } \\
\text { (cf.pp.14,15) }\end{array}$ & $\begin{array}{l}\text { Nominative } \\
\text { Janek lubi Marysię. } \\
\text { "John (NOM) likes Mary.” }\end{array}$ \\
\hline
\end{tabular}




\begin{tabular}{|c|c|c|}
\hline $\begin{array}{l}\text { Direct object of a } \\
\text { verb (DO) }\end{array}$ & $\begin{array}{l}\text { Follows V+ IO (cf. p.17) } \\
\text { or follows and is adjacent to } \\
\text { V } \\
\text { John gave Mary a book. } \\
\text { John likes Mary. }\end{array}$ & $\begin{array}{l}\text { Accusative (with negation - } \\
\text { Genitive) } \\
\text { Janek lubi Marysię. } \\
\text { “John likes Mary (ACC).” }\end{array}$ \\
\hline $\begin{array}{l}\text { Indirect object of a } \\
\text { verb (IO) }\end{array}$ & $\begin{array}{l}\text { Follows and is adjacent to } \\
\text { "to" (b) or follows and is } \\
\text { adjacent to V (a) } \\
\text { (a) John sent Mary a letter. } \\
\text { (b)John sent a letter to } \\
\text { Mary. }\end{array}$ & $\begin{array}{l}\text { Dative } \\
\text { Janek wystat Marysi list. } \\
\text { "John sent Mary (DAT) a letter." }\end{array}$ \\
\hline $\begin{array}{l}\text { Object of a } \\
\text { preposition } \\
\text { (PO) }\end{array}$ & $\begin{array}{l}\text { Follows and is adjacent to } \mathrm{P} \\
\text { John looked at Mary. }\end{array}$ & $\begin{array}{l}\text { Follows and is adjacent to P } \\
\text { Janek patrzy na Marysię } \\
\text { "John looks at Mary." }\end{array}$ \\
\hline Subject of an NP & $\begin{array}{l}\text { Follows and is adjacent to } \\
\text { DP / NP boundary, Saxon } \\
\text { genitive } \\
\text { John's photos from Florida }\end{array}$ & $\begin{array}{l}\text { Precedes N, Genitive } \\
\text { Janka zdjęcia z Florydy } \\
\text { John(GEN) pictures from Florida }\end{array}$ \\
\hline $\begin{array}{l}\text { Object/complement } \\
\text { of a noun }\end{array}$ & $\begin{array}{l}\text { Object of the preposition } \\
\text { "of" in a post-nominal PP } \\
\text { John's pictures of his wife }\end{array}$ & $\begin{array}{l}\text { Follows N, Genitive } \\
\text { Janka zdjęcia swojej żony } \\
\text { (GEN) }\end{array}$ \\
\hline
\end{tabular}

Each of the syntactic functions in the table are linked to a unique DF. Each DF is defined as a bundle of morphosyntactic properties, which will be called its diacritic specification. The properties of which it consists will be called diacritic features. For each function in the table we have a different combination of such features. The features include morphological case or the position with respect to the main verb, noun, or preposition.

The claim that USIR isa parser's demand (PROS), not a grammatical constraint, finds support in the way it is formulated, its scope of application and the nature of the evidence for it.Firstly, note that USIR requires differentiation but it does not specify the exact form of it, which might be typical of parsing-related conditions. ${ }^{9}$ As regards the nature of the evidence for USIR, the differentiation which it requires has not always been grammaticalized. As it has been shown in the previous section, this is a characteristic property of a PROS, which can but need not always be grammaticalized. Grammar's response to the parser's demands could be a language-specific rule or parameter value, but sometimes this is not possible for grammar-internal reasons. In such cases the violation of the

\footnotetext{
${ }^{9} \mathrm{cf}$. Fodor (1984) on the relationship between constraints on gaps and parsers' demands. The parser requires constraints but need not determine their exact form.
} 
constraint results in sentences being not ungrammatical but odd, clumsy, difficult to process. Stylistic variants are preferred if available, and the feeling that there is something wrong with the construction in question diminishes once context or lexical content help in assigning meaning to it, thus easing the job for the syntactic parser.

Consider the English nominals in 18. (after Kayne: 2015 ).

18. a. Gift of the money to the children

b. Removal of the money from children

c. *Deprivation of the children of the money

18. violates USIR as two NPs have the same diacritic specification (DF) (follows and adjacent to the preposition "to". If 18. is ungrammatical, as stated in Kayne 2015, USIR provides functional motivation for the grammatical rule/constraint involved.

Consider next the genitive specifier/subject NP in Polish. It can be moved to the post nominal position. If a genitive complement is present, there is a violation of the identification requirement as both genitive NPs follow the head noun. We have the following configuration of data:

19. a. Janka przyjazd

John's (GEN) arrival.

b. przyjazd Janka

arrival Janek (GEN)

"John's arrival"

20. a. Janka pobicie Wojtka John (GEN) beating Wojtek (GEN)

b. ?? pobicie Wojtka Janka beating Wojtek(GEN) Janek (GEN)

"John's beating of Wojtek"

21. a. Janka portret Wojtka

John (GEN) portrait Wojtek(GEN)

b. ?? portret Wojtka Janka portrait Wojtek (GEN) Janek (GEN)

"John's portrait of Wojtek"

22. a. Janka zaproszenie Wojtka

John (GEN) invitation

Wojtek(GEN)

b.?? zaproszenie Wojtka Janka

invitation Wojtek (GEN) Janek (GEN)

"John's invitation of Wojtek"

19.b. shows that genitive specifier postposing is possible. The same operation leads to problems when a genitive complement is also present (20.b.-22.b), which could be attributed directly to USIR. Both NPs are 
characterized by the same diacritic features - the genitive case and post nominal position.

Note that the strangeness of 2o.b.-22.b. is not a simple consequence of their ambiguity. The equally ambiguous (in both languages) NPs in 23. are perfectly all right.

23. a. fotografia Janka

"John's photo"

b. zaproszenie Wojtka

"Wojtek's invitation"

c. upomnienie nauczycielki

"teacher's warning"

What is wrong with 20.b.-22.b. is that they contain two NPs which are not properly "uniquely identified" and thus "differentiated" from each other, which we assume is what the parser requires for its efficient operation.

Note that, as USIR predicts, the unacceptability disappears when the complement phrase is in a different case, e.g. instrumental, or is preceded by a preposition as in:

24. a. machanie ręka Janka waving hand (INSTR) John(GEN)

"John's waving his hand"

b. pomysty [na życie] Janka ideas[for life] John(GEN) "John's ideas for life"

The naturalness of 24. and the oddness of 20.b-22.b indicates that USIR is not a grammatical constraint but a PROS. Apparently, a syntactic rule would not be able to block the postposing of genitive NP specifiers just in case a genitive and not dative complement occurs in the same NP. Evidently syntactic rules operate independently of such morphological factors.

For further support for this conclusion consider 25. If the lexical content of the genitive NPs suggests interpretation unambiguously, the construction is much more acceptable.

25. a. ?zdjęcia Wojtka tego fotografa pictures Wojtka (GEN) that photographer (GEN) "that photographer's pictures of Wojtek"

b.. ?portret Arystotelesa Rembrandta portrait Aristotle(GEN) Rembrandt(GEN) "Rembrandt's picture of Aristotle"

Still another factor which may influence judgments is the availability of a paraphrase that does not run into problems with respect to the identification requirement. If such a paraphrase is available, the 
inappropriateness of the construction is more acutely felt, which might account for the difference between 21.b., which seems better (no paraphrase) than 20.b and 22.b.. which could be paraphrased (cf. "pobicie Wojtka przez Janka" ("beating of Wojtek by John")).

Perhaps the strongest evidence against USIR as a grammatical constraint is the peculiar way in which it is restricted in its scope. As noted above, it applies to phrases the processing of which (e.g. assignment of semantic function, identification of antecedent etc.) requires reference to its structural position within some theta domain. It does not apply to adjuncts like this way, that night, the interpretation of which relies on their lexical content.

\section{6. a. He talked to Mary about Betty [this way][last night] \\ b. Janek nie widziat Marysi[tej nocy] "John did not see Mary (GEN) that night (GEN)" \\ c. Jacek rzadzit [ta metoda] [swoja firma] "John ruled his company(INSTR) this way(INSTR)."}

In the foregoing discussion it has been shown that USIR applies to phrases (arguments and nonarguments) in argument positions. However, the way we have defined the scope of the constraint, it should also be applicable also to phrases dislocated by movement rules to non-argument positions. In a language like English, for the proper interpretation of such phrases the parser has to link them to their "pre-dislocation" argument positions, which are occupied in grammatical representation by non-phonological elements (traces/copies) or "shadow" pronouns. In these positions the parser locates GAPS, for which the dislocated phrases are identified as FILLERS. There is considerable experimental evidence that such a processing operation takes place in movement constructions. ${ }^{10}$ Given our assumptions about the scope of USIR, the constraint should be applicable to both FILLERS and to GAPS. This will include NPs moved to non-theta argument positions by NP movement (passives and raising structures) as well as fronted interrogative and relative pronouns and topicalized NPs in non-argument positions at the leftward periphery of a clause. The second case involves a DF which in English will be claimed to have in English a diacritic specification that makes reference to the position of the fronted phrase - to the right and adjacent to the clause boundary - as in the $\mathrm{CP}$, as in 27 below.

\section{7. a. [ [Which book] did John read GAP ] $\mathrm{CP}$ \\ b. [..[The boy] John met GAP at the party] $\mathrm{CP}$}

The ungrammatical multiple question in 28. violates USIR since both whphrases have the same DF adjoining a CP boundary in a multiple $\mathrm{CP}$ specifier

${ }^{10}$ Cf. Fodor 1978,1983, Stowe 1986,Bever et al. 1988, Featherston 2001, among others. 
structure. We will return to the problem of multiple frontings in the next section.



As formulated in 9., USIR, which we consider to be a fundamental principle of syntactic "diacrisis", is extremely general, and it does not motivate directly any specific grammatical rule or principles. It requires differentiation but it does not constrain it. In fact, insofar as the "semiotic" motivation for USIR is concerned, this level of generality is all that is required. It would seem natural however that from the psychobiological perspective of the parser not all imaginable types of "differentiation" or "identification" are equally admissible. This is due to limitations of the systems of auditory perception, pattern recognition, memory storage and other cognitive resources involved in parsing. Diacritic features must be perceptually transparent.

Just as affixes must conform to certain conditions in order to fulfill this requirement (they have to be "hearable", hence general avoidance of zero morphs; the rightward periphery of a word is perceptually more prominent, hence inflectional suffixes not prefixes etc.) one could expect that there are some perceptually motivated restrictions on the possible ordering relationships of free forms. We might imagine, for example, that a parsing instruction that would involve an NP identified as the third NP from the left would not be easy to execute. Or the one which applies to the word which is exactly in the middle of the sentence, i,e. has an equal number of words to its right and to its left.

Such extreme cases of what the parser would have problems with are much easier to give than cases which will be easiest, i.e. most preferable by the parser. In what follows, we will suggest two such preferences for which we will claim the status of PROS.

\section{Local Function Marking Requirement (LFMR)}

Diacritic Functions (DFs) are marked locally.

Assume that there are two basic DF markers for NPs: affixation (morphological case) or positioning with respect to some other free element. Marking by affixation is by its nature local. In the second case, however, non-local marking is logically imaginable. For example, the fact that a given NP just follows the main verb could potentially be the sign of its being a direct object of that verb.

\section{0. *John [sold to Bill unexpectedly [his old car] for hundred bucks]}

Our constraint would exclude such diacritic feature with a prediction that it is either not grammatically realized or highly marked. 
Note that we treat the free forms like transitive verbs, prepositions, and perhaps other heads of phrases, as having a diacritic status comparable to that of morphological case affixes. They all can be diacritic features providing diacritic specification for NPs and allowing them to meet the identification requirement. In what follows we will show that also some constituent boundaries can function in the same way.

In positional languages, the general concept of "locality" referred to in 29. can be restricted to "adjacency" This results in a strong constraint on word order:

\section{The Adjacency Requirement (AR)}

If a diacritic feature of an NP refers to its ordering with respect to some other element, the preferred type of ordering relationship is that of adjacency.

The relationship between ordering and syntactic/semantic function with which we are concerned here is that which is incorporated in some parsing instruction. In other words, the parser is assumed to use the ordering as an essential clue for the identification of the NP. The ordering information need not be incorporated directly and explicitly into any grammatical rule which refers to the NP in question. For example, it is likely that the parser for English would include instructions like: assign to the NP immediately following the verb the grammatical function of the direct object of that verb. The language-specific diacritic feature that the parser makes use of need not (and does not) enter a grammatical definition of the function of direct object, where functions receive possibly universal configurational definitions (eg. "Direct Object is a sister of $\mathrm{V}$ and a daughter of V'). The fact that the a "bare" NP has to be adjacent to the transitive verb in VP and to the head preposition in PP can simply be stipulated by language specific rule(s) (or parameter values) to exclude in English (a positional language) cases like:



Assuming a GB-type theory of abstract case, we can have a language specific setting of the parameter "adjacency/non-adjacency" on abstract case assignment/checking which generalizes over 32 . a and 32.b.The Adjacency Requirement, which is a PROS, provides a functional explanation for the "adjacency" setting in English.

Why should there be a condition like AR? It may simply be that the parser cannot count (cf. Berwick and Weinberg 1984) or/and that the nonadjacent orderings may lead to confusion if more than one item of a given category could occur to the left or right of some element with which it is supposed to be linked (only one element can be adjacent).

Considering the diacritic features in the table in 17., we observe that in English grammar's response to the adjacency requirement is straightforward in three 
cases: direct/indirect object and transitive verb, prepositional object and preposition., fronted wh- phrase and the $\mathrm{CP}$ boundary. Other cases require discussion.

Consider subjects in English. They have been tentatively identified in 17. as the NPs which precede the verb. Of course, this must be reconsidered, as we can have adverbs between the two elements, which means there is no required adjacency.

33. John probably often drunk vodka.

The table in 34. shows typical syntactic contexts of subject NPs in English.

34

a. [ $\mathrm{CP}$

b. [ $\mathrm{CP}$

c. [ $\mathrm{CP}$

d. [ $\mathrm{CP}$

e. $[$ Wh$\mathrm{CP}$

f. [ $\mathrm{CP}$

g. $[\mathrm{NP}$ $\mathrm{CP}$

h.
NP Aux VP IP
John will go .

That John will go...

For John to go....

Whom will John meet?

....whom John will meet

Will John go?

Mary John would like to kiss.

I want John to go.

In 34. a.-g, the diacritic feature could be the adjacency to IP. In 34.h., the adjacency to V. To account for cases like 35., with pre-subject sentence adverbs, we will introduce the notion of "weak" adjacency, which could be defined as in 36 .

35. I know that [yesterday John was not here]

36. Element $X$ of the category $A$ is "weakly" adjacent to $Y$, where $Y$ is a constituent boundary, iff there is no $Z$ of the category $A$ intervening between $A$ and $B$ 
It is possible that in 34.c.d.f. the subject is identified as being adjacent to $\mathrm{C}$. 37 . shows that the adjacency is obligatory.

37. a. *For often John to leave the party

b. *(Whom) will often John invite to his birthday party?

This would mean that the same grammatical function "subject" could be "realized" by two (or more) different DF's in different contexts in different constructions (which 9. allows).This would be a situation similar to that in 38., where the indirect object is (in 38.a.) adjacent to $\mathrm{V}$ or to $\mathrm{P}$ to (in 38.b.).

\section{8. a. John gave Bill a book \\ b. John gave a book to Bill}

Apparently, the uniqueness requirement (and other principles of syntactic diacrisis) is "syntagmatic" in nature, i.e. it regulates relations among syntactic units within a sentence rather than within the grammatical system. Of course, a grammatical system in which the same function would have a variety of different context-dependent diacritic specifications would probably be in many ways inefficient, more difficult to acquire and use. This, however, might be a different type of external pressure on the language system, the tendency for "unique identification" being primarily, if not only, restricted to elements of the same clause (or more precisely of a theta-domain).11

Note that relativization of the uniqueness requirement to a given theta domain is needed also in inflectional languages. For example, in Polish the direct object can be marked by either accusative or genitive (in all negative sentences) (nie mam pieniędzy/mam pieniadze ) and with some verbs like potrzebować (need) szukać (seek) nienawidzieć (hate), or by instrumental (with verbs like rzqdzić(govern), sterować (steer). The USIR is obeyed as long as the direct objects are not in dative (reserved for indirect objects) or nominative (reserved for subjects).

The last rule of diacrisis to be proposed concerns the restriction on the set of what we will call "pointers"- the elements that show up in the diacritic specifications of NPs in positional languages.

39."Pointers"

If a phrase is identified on the basis of its ordering with respect to some element $X, X$ must belong to the designated set of "pointers".

${ }^{11}$ The morphonological diacrisis seems to be different. The distinctive/diacritic features are relevant primarily, if not only, for paradigmatic identification of phonemes. This is because phonetic segments do not have any specific functions which distinguish them from other segments. The only meaning-relevant syntagmatic relationships they enter are being a part of some specific morpheme and preceding/or following other segments (or strings of segments). 
"Pointers" are elements thatare in a sense most prominent perceptually in a construction, constituting a stable positional reference point to which argument NPs could be "anchored". The sets of "pointers" may be different for different languages (language types) or there might be a universal set of such elements from which languages can chose. We will leave this as an open question for further research. It would be ideal if an independent characterization of "perceptual prominence" or similar concept could be given which could motivate pointer choice, but at this point we can rely on stipulation only.

40 For English the set of "pointers" are:

i) heads of $V P, P P, C P$

ii) the constituent boundaries: $C P, I P, N P$

Finally, we will make two additional assumptions:

41. i) The direction of "pointing" tends to be uniform for a language.

ii) Each "pointer" can license one adjacent element only (thus providing unique identification)

Note that 41. ii) follows from 41.i) and the Adjacency Requirement in 31.

For lexical elements as pointers, the direction can vary cross-linguistically, while for phrasal boundaries it might be constant, to the right in all cases except for the final CP boundary. This implies that the position at the beginning of some phrase ([ XP X ... ) is more prominent than the final position ([ $\mathrm{XP}$...X] $]$ ). This is a natural assumption because it is the beginning of a phrase that is usually signaled in some way (a complementizer or determiner - in the case of "extended projections" (in the sense of Grimshaw 1990) of $\mathrm{V}$ and $\mathrm{N}$ respectively). Actually, the information signaling that a constituent has been finished/completed is external to it and comes usually from the properties of the first element of the following phrase or clause. What is signaled is thus usually "here begins constituent X", which appears to be the typical boundary pointer function.

Given 31.,40., and 41., potential problems arise with English double object constructions and constructions with topicalized NPs as in 42.

\section{2. a. [This person [John would never invite to his birthday party]]. ? IP \\ b. John gave [this girl] [a book]}

If we assume the topic to be a specifier in CP, (i.e. ? in $42 .=\mathrm{CP}$ ) the problem disappears with the $\mathrm{CP}$ boundary as the pointer. That this is indeed the case is shown by sentences like 43., where topicalization of a PP triggers inversion.

43. [With no money [will] [John be happy]] CP $\mathrm{C}$ IP 
Tadeusz Zabrocki: Syntactic diacrisis in arigid and a free word order language

On the other hand, we have sentences like 44., which might indicate that the topic is adjoined to IP as a kind of second specifier in IP, which might be problematic for USIR.

\section{4. ? I think [ that [ this person [John will never invite ]] $\mathrm{CP}$ ? IP}

A solution would be to assume that in 44 . we have two CPs (i.e. ? in 44. $=\mathrm{CP}$ ). This analysis, compatible with 31.,40., and 41., is supported by examples like 45 .

45. Mr Teague said [ that [at no time was [Paul John ever hit with $C P \quad C P \quad$ a cane or whip.

(Biber at al. p. 919)

Note that in 44. the USIR is not violated, as one of the two elements with the same diacritic feature (adjacency to CP) is a complementizer, which is not subject to the constraint.

When an NP is moved to SPEC/CP position the topicalization is not possible

46. *I know [which girl [this person [Mary introduced to?]]] CP CP IP

The double object constructions as in 47. pose another potential problem for our account.

\section{John sold [Bill] [a car].}

Several different analysis of the constituent structure of 46 . have been proposed:

48. a. John [ [ sold [Bill] [a car] ] ] DO and IO as sisters VP V'

b. John [ [ [ sold [Bill] ] [a car] ] ] DO adjoined to "small VP" $\mathrm{VP} \mathrm{V}^{\prime} \mathrm{V}^{\prime}$ c. John $\underset{\mathrm{VP}}{[} \operatorname{sold}_{i} \underset{\mathrm{VP}}{[\text { Bill }]\left[t_{i}[\boldsymbol{a} \text { car }]\right]} \underset{\text { (Larson 1988) }}{\text { "VP shell” }}$

While in 48.a. the direct object is not properly identified, accepting 48.b. requires the addition of $\mathrm{V}$ ' to the set off pointers, which we would like to avoid given the dubious "perceptual prominence" of that boundary.

The VP shell analysis could solve the problem with some additional assumptions. We will extend the set of pointers in English by adding the trace of head movement. If so, the two NPs, Bill and a car would be identified by two unique pointers - the verb sold and its trace. 
This seems reasonable as traces of heads, unlike traces left by phrases, are easily detectable ("visible") at SL. This follows from the highly constrained nature of the head movement. The trace is always located in the position of the head of the complement of the filler, which means that the parser does not have to search for the gap. The trace of $\mathrm{V}$ could be in two positions only: a) between $\mathrm{V}$ and the NP that follows it (the "vacuous movement"), in case the verb is mono-transitive or the IO is a "to" $\mathrm{PP}$, or b) between two "bare" NPs following a ditransitive verb. The choice depends on a simple observation if the verb is followed by two "bare" NPs. The diacritic specification of two types of objects will be as follows a) direct object adjacent to the trace of $\mathrm{V}, \mathrm{b}$ ) indirect object - adjacent to $\mathrm{V}$ or to the preposition "to". 12 The above analysis, if correct, confirms our conjecture (cf. fn. 7 above) that USIR applies not at the grammatically defined interface level but to structures that have undergone some initial "preprocessing". They are like Phonological Representations of generative grammar but "enriched" with phonologically empty elements (trace, PRO) whose presence in specific syntactic positions is predictable from the information contained in lexical entries - i.e. obligatorily ditransitive verbs imply a V-trace between indirect and direct object, a passive participle implies a trace in direct object position (in Polish). It might then be possible to account for "small clause" constructions like 49 . by having USIR applied to the structure where the subject complement NP is preceded by and adjacent to an "empty" linking verb.

\section{I consider [Bill [ e] a traitor]. $\mathrm{V}$}

\section{English and Polish; some diacrisis-related differences}

In this section we will ty to show that the principles of syntactic diacrisis have different consequences for the grammatical structure of English and Polish. The differences follow from Polish being an inflectional language with a rich system of morphological cases and English being "positional" one with word order as the most important diacritic feature in NP identification.

\footnotetext{
${ }^{12}$ It should be noted that in double object constructions the ditransitive verbs usually require [+human] indirect objects and [-human]. direct objects. This should provide an extra pragmatic/semantic diacritic factor. It does not come under USIR, but might facilitate the processing (cf. the comments on 25. above). Note also that the ditransitives which usually take both, [+human] objects like introduce, recommend require the IO to be accompanied by a preposition.
}

Mary introduced/recommended [this person] [ to John].

${ }^{*}$ Mary introduced/recommended [John] [this person]. 


\subsection{Abstract Case assignment/checking}

In the GB theory of generative grammar the Case Filter requires phonological ("non-empty") NPs to have abstract syntactic Case in surface structure. The Case is assigned/checked by case assigners/checkers (P, V or Tense/Agr) under two conditions: a) that the assigner/checker governs the $\mathrm{NP}$, and $\mathrm{b}$ ) that it is adjacent to the NP. The first condition was assumed to be universal, the second language specific. ${ }^{13}$

The violation of the adjacency restriction accounts for the illformedness of the English in 50.a.-54.a below. The examples in 50.b-54.b , where adjacency holds, are well formed.

50. a. *Max introduced yesterday his wife to Jack.

b. Max introduced his wife to Jack yesterday.

51. a. * John told yesterday Mary this old joke.

b. John told Mary this old joke yesterday.

52. a. *For loudly Mary to complain was surprising.

b. For Mary to complain loudly was surprising.

53. a. *He wants now Mary to come to the party.

b. He now wants Mary to come to the party / He wants Mary to come to theparty now.

54. a. *John went to straight the boss.

b. John went straight to the boss.

The Polish counterparts of 50.a, and 51.a are grammatical sentences. Apparently the adjacency parameter is set differently in that language.

55. a. Max przedstawit wczoraj swoją żonę (ACC) Jackowi. (counterpart of 50.a.)

b. John opowiedziat wczoraj Marysi (DAT) ten stary kawat. (counterpart of 51.a.)

Sentences in 52. and 53, have no counterparts in Polish, which lacks Exceptional Case Marking structures (no ACI constructions and no case assigning/checking preposition-like infinitive complementizer for). As for 54. the Polish counterparts are also ungrammatical (“*On poszedt do prosto szefa") This, however, seems due to an independent restriction on preposition modifying adverbs that requires them to precede the preposition. This restriction is shared by both languages as shown in 56 .

56.a. *John went [to the boss straight],

13 see Chomsky (1981, p.94) "we might assume this [adjacency of an NP to its case assigner (T.Z.)] to be one of the unmarked options for Case Theory". It is unclear how the adjacency facts are accounted for in more recent generative approaches where abstract cases are assigned to specifiers of functional heads. 


\section{b. *Janek poszedt [do szefa prosto]}

In fact, under certain conditions Polish prepositions can be separated from their objects by interpolated VP adverbs.

\section{7. ? Pomiędzy wówczas [napastnikiem, a jego ofiara] stanąt Janek. between then [the attacker and his victim] stood John "Then John stood between [the attacker and his victim]."}

58. shows that also other elements can stand before a preposition and its object

\section{Janek przeciwko glosowatby obecnie [jakiejkolwiek partii nacjonalistycznej]. \\ John against would-vote presently [any nationalist party]. "John would presently vote against any nationalist party."}

Within the theory of syntactic diacrisis, this parametric difference between English and Polish receives a straightforward (functional) explanation. Adjacency to case assigning transitive verbs is a diacritic feature in English, but not in Polish where objects fulfill the identification requirement of USIR by their case affixes - Accusative in 55.a. and Dative in 55.b.

Note that in either language the adjacency requirement is not applicable to adjunct NPs such as "this evening/tego wieczoru", "this way/tym sposobem". They are also exempt from USIR.

\subsection{Multiple Fronting}

It is well known that English prohibits multiple fronting of phrases. Only a single wh-phrase or a single topic NP can precede the subject. Whatever grammatical parameter is involved here, the diacrisis theory provides functional motivation for the different way it is set in both languages. As it has been claimed in section 3. (cf. 28.), English sentences like 59. violate USIR, as the NPs "which girl" and "this person" have an identical diacritic feature - they are adjacent to $\mathrm{CP}$ (have $\mathrm{CP}$ as a pointer)

\section{9. *I know [which girl [this person [Mary introduced to?]] ] $\mathrm{CP}$ \\ $\mathrm{CP}$ IP}

The syntactic constraint against multiple fronting has a general nature in English and blocks both multiple Wh-Movements and multiple Topicalization.

6o. a. * [ Whom [ whom [ did Mary introduce to ]]]? 


\section{b. $\quad *[$ Jack [ Mary [ Bill introduced to $]]]$.}

Whatever the right grammatical account for 59. and 60., it is clear that the way the parser's demand has been grammaticalized involves some amount of "overkill", i.e. has consequences that go beyond what diacrisis would require Whatever blocks multiple NP fronting would prohibit also multiple PP fronting and multiple fronting of adjunct wh-elements as in 61., though this restriction has no processing motivation in our account. PPs (prepositions locally identify their object NPs) and the adjunct phrases are not subject to USIR.

61. a. *[To whom] [about whom] did John talk?

b. ${ }^{*}$ I do not know [to whom Mary John introduced]?

c. ${ }^{*}$ Whom when did you help?

As pointed out in section II, this is a common situation with processing motivated grammatical constraints. The requirements of the processor are reflected in the grammatical system only in the form and to the extent that is compatible to the processing-independent constraints on the form and functioning of grammatical rules. Apparently, the processing related distinction between various types offronted phrases would be difficult to incorporate within the grammatical solution offered in English to the processing problem.

Whatever grammatical restriction blocks59.-61. ( let us assume after Lasnik and Saito 1984 that it is the impossibility of adjunction to IP ), it is not present in Polish, in which multiple frontings are grammatical. ${ }^{14}$

62Komu kogo Marysia przedstawita? Whom (DAT) whom (ACC) Mary introduced

63. Janka Wojtkowi Marysia przedstawita. John (ACC) Wojtkowi (DAT) Mary (NOM) introduced

64.Komu o kim Janek mówit? Whom (DAT) [about whom] Janek (NOM) talked.

65. Nie wiem komu Jacka Marysia przedstawita. not I-know whom (DAT)Jack (ACC) Mary (NOM) introduced

In 62., 63. and 65. the fronted NPs are uniquely identified by their case affixes, which serve as their diacritic features.

Multiple frontings are allowed without any restriction on the number of fronted phrases:

66. Kto kogo komu kiedy przedstawit?

Who (NOM) whom (ACC) whom (Dat) when introduced?

"Who introduced whom to whom when?"

\footnotetext{
${ }^{14}$ Note that if adjunction to IP had been possible, we would have a violation of USIR in English on the assumption that the IP boundary is also employed as a "pointer" for the subject.
} 


\subsection{Right Node Raising}

Right Node Raising has traditionally been used as a convenient constituency test in English.

67. a. John accepted but Mary refused this expensive gift.

b. * John wanted to sell but Jack decided to give Mary that old car. ( with the meaning: John wanted to sell Mary that old car but Jack decided to give Mary that old car)

Constructions like 67.b. are grammatical in Polish.

68. Janek chciał sprzedać, ale Jacek podarowat Marysi rower. John wanted to sell * (Mary a bicycle) but Jack gave Mary a bicycle

If Right Node Raising involves some kind of across-the-board movement to the end of the clause, the situation here resembles that observed in connection with fronting rules. Polish allows for a multiple application of the rule in a single clause and English does not.

As in the case of multiple fronting, the grammatical difference between the two languages may be related to the fact that the target position for the across-the board extraction is "licensed" by a single pointer - the end of clause CP boundary. ${ }^{15}$ Only the second of the two post-posed NPs can be licensed this way. Apparently, the first one, the indirect object, cannot be identified by the transitive verb. As predicted, the verb-object adjacency requirement does not hold in such structures:

69. John refused immediately but Mary accepted eagerly Bill's offer to help.

In the Polish example in 68, the unique identification is assured by the dative and accusative case suffixes. English.

A similar restriction on multiple movements applies to Heavy NP Shift in

70. * I recommended yesterday evening that young girl with a red skirt that

inexpensive Italian restaurant downtown.

15 41. i) must be modified to allow for CP to point to the left. We should also define "adjacency" in 31. as in i) below.

i) " $\mathrm{X}$ and $\mathrm{B}$ are adjacent if no $\mathrm{Y}$ intervenes between them, where $\mathrm{Y}$ is a phonologically non-empty word, morpheme or a boundary pointer".

Note that the right IP boundary in ii) below is not a pointer for X , if we assume that, unlike CP, IP can point to the right only.
ii) $(. . . . \mathrm{X})$
IP CP 
As expected, corresponding structures in Polish are grammatical.

71. $\quad$ Polecilem wczoraj tej młodej dziewczynie $w$ czerwonej spódnicy tq niedrogą wloska restauracje $w$ śródmieściu

3.4 Word order freedom - " positional template" and scrambling

The requirement of being adjacent to a "pointer" limits the number of permissible NP positions in a positional language. This creates a syntactic pattern, which we will call a "positional diacritic template" (PDT). In view of what has been claimed above, the template for an English clause would be as in 72., with five basic NP positions. Each of them is linked to a different DF.



The template in 72. shows only those NPs and PPs which are immediately dominated by one of the categories of the "extended projection" (in the sense of Grimshaw 1991) of V -V',VP, IP , CP. An additional position/DF is that of NP object of a preposition:

73. ${ }_{\mathrm{PP}} \mathrm{P}$ NP $]$

6

The template is language specific insofar as the set of boundary pointers and the position of the verb in VP are subject to variation across languages. For example, the positional verb final language would provide for a pre- instead of post-V position.

Below are the positions (i.e. DFs) in 72. and 73 .

DF 1 (adjacent to CP) - the position of the topic phrase and of the fronted Wh- phrase.

DF 2 (adjacent to IP) - the position of a subject

DF 3 (adjacent to Vtr) - the position of the direct object and, in double object constructions, of the indirect object

DF 4 (adjacent to "empty" V) - the position of the "second object" (direct object or NP predicate of a small clause)

- adjacent to V-trace or empty linking verb

DF. 5 ( clause final-adjacent to the right CP boundary) - the target position of the Heavy NP Shift

DF. 6 (adjacent to P) - the position of the object of a preposition 
PDT expresses the diacritic syntactic preference of the parser. The six positions will be the "most natural" or unmarked in a non-inflectional language. The "positional template" does not apply in an inflectional language such as Polish. This removes functional motivation for the grammatical restrictions on IP adjunction (multiple fronting) and the adjacency condition on Case assignment/checking. In fact it removes all diacrisis related restrictions on PR positions of NPs within the extended projection of V. This, in turn, allows the "scrambling" of NPs in Polish (and other Slavic languages), yielding a full set of twenty four possible Subject, Verb, Direct Object and Indirect Object word order configurations in 74 .

74.

Janek przedstawit Marysi Marka. Janek przedstawit Marka Marysi. Marysi przedstawit Marka Janek. Marysi przedstawit Janek Marka. Marka przedstawit Marysi Janek. Marka przedstawit Janek Marysi.

Marysi Janek przedstawił Marka. Janek Marysi przedstawił Marka. Marka Marysi przedstawił Janek. Marysi Marka przedstawit Janek. Janek Marka przedstawit Marysi. Marka Janek przedstawit Marysi.
Janek Marka Marysi przedstawit. Marka Janek Marysi przedstawit. Marka Marysi Janek przedstawit. Marysi Marka Janek przedstawit. Janek Marysi Marka przedstawit. Marysi Janek Marka przedstawit.

Przedstawit Janek Marysi Marka. Przedstawit Janek Marka Marysi. Przedstawit Marysi Janek Marka. Przedstawit Marysi Marka Janek. Przedstawit Marka Marysi Janek. Przedstawit Marka Janek Marysi.

All sentences in 74. have the (logical) meaning of English 75. The English sentence has only two possible variants with pre-subject topics.

75. a. John introduced Mark to Mary.

b. Mark, John introduced_to Mary.

c. Mary, John introduced Mark to_.

In each sentence in 74 all three NPs have different morphological cases: nominative -( Janek), dative (Marysi) and accusative (jabłko). However, even in a language with such a rich inflectional system, two NPs in the same theta-domain can be phonologically undistinguishable. This may happen in several situations. The first case is illustrated by 76. 77., where the direct object with an (inherent) instrumental case is followed by a non-argument NP with the same case.

76. Janek sterowat todzia wiostem. John steered boat (INSTR) oar (INSTR)

"John steered the boat with an oar."

77. Ta partia nie będzie już rządzić krajem wiosna 
Tadeusz Zabrocki: Syntactic diacrisis in arigid and a free word order language

this party not will any-more govern country (INSTR) spring (INSTR)

"This party will not govern this country any more in spring."

76.-77. are not a problem for USIR, as the second NP is an adjunct? Its semantic function is determined by both the type of morphological case and the lexical meaning of the head word.

Another example involves sentences with verbs subcategorizing infinitive complements. In Polish, such constructions involve a "clause union" whereby construction with two predicates behaves in several respects as a single syntactic clause. While the extraction from finite clauses is very restricted, the infinitive clause boundary is transparent for scrambling, topicalization and wh-movement:

78. a. Matka kazała Marysi zjeść śniadanie. mother(NOM) ordered Mary(DAT) to-eatbreakfast(ACC)

b. Matka Marysi śniadanie zjeść kazała. mother(NOM) Mary(DAT) breakfast(ACC) to-eat ordered

c. Marysi śniadanie matka zjeść kazata. Mary(NOM)breakfast(ACC) mother(NOM) to-eat ordered "Mother ordered Mary to eat breakfast."

79. Kogo komu Janek kazat poszukać?

Whom(ACC) whom(DAT) John ordered to look for?

"Whom did John order to look for whom?"

A potential problem for USIR can come from "clause union" structures where complements of the finite and nonfinite verbs have the same morphological case:

8o. a. Janek kazat Marysi pomóc Jackowi. John ordered Mary (DAT) to-help John (DAT)

b. ? Marysi Jackowi kazał Janek pomóc. Mary (DAT) Jack (DAT) ordered John (NOM) to-help "John ordered Mary to help Jack."

81. ? Której dziewczynce któremu chtopcu Janek kazat pomóc? which girl (DAT) which boy (DAT) John ordered to-help "Which girl did John order to help which boy?"

82 .a. Marysia nauczyła Janka szanować Basię. Mary taught John (ACC) to-respect Jack (ACC)

b. ? Janka Basię Marysia nauczyła szanować. John (ACC) Barbra (ACC) Mary (NOM) taught to-respect "Mary taught John to respect Jack."

83. ? Kogo kogo Marysia nauczyła szanować? whom (ACC) whom (ACC) Mary (NOM) taught to-respect "Whom did Mary teach to respect whom?" 
As 80.a. and 82.a. show, if complements follow their subcategorizers, the sentence is perfectly acceptable. If both complements are fronted, the sentences become confusing and are judged by many speakers as unacceptable. Evidently, the difference has to do with the left-to-right parsing process. All three arguments (subject, indirect object and the nonfinite clause) of the extended projection of the predicate kazat in 80.a. and nauczyła in 82.a. are properly identified and assigned their semantic functions as soon as the parser reaches the infinitive complement. At this moment the interpretation of one extended projection/theta domain is completed and the parser proceeds to the next one, where it comes across the complements of podziękowac and szanować.In this way USIR is obeyed, as the identification of NP arguments remains unique relative to their theta domains. This is not the case in 80.b., 81., 82.b. and 83., with fronted complements. Here the linear demarcation of the two domains is impossible. In consequence, the whole construction is being treated by USIR as one super-domain, an extended projection of a complex of four argument predicates kazat-podziękować (80.-81.) and uczyła szanować (82.-83.). This accounts for the oddness of these Polish sentences, which are confusing but hardly ungrammatical. The parsing requirement has not been grammaticalized here for grammar-internal reasons. Evidently, it would be difficult to make movements to non-argument positions dependent on the specific type of morphological case.

Characteristically, unacceptability decreases when non-structural, lexical factors facilitate unambiguous interpretation. This confirms the status of USIR as PROS.

\section{Któremu harcerzowi której staruszce Janek kazat pomóc? which boy-scout (DAT) which old-lady(DAT) John ordered to-help \\ "Which boy scout did John order to help which old lady?"}

Another situation in which an NP is moved from one extended projection/theta domain to another with the resulting loss of the phrase's unique identification is shown in 86 . Here, a genitive modifier of a noun is extracted from NP and topicalized. While 85. is acceptable,86. is not, although again the ungrammaticality is not involved.

85. Nie spotkat [ojciec Marysi] Wojtka na przyjęciu. not meet father(NOM) Mary(GEN) Wojtek(GEN) at party "Mary's father did not meet Wojtek at the party."

86. ? Marysi Wojtka dziś nie widziat ojciec Mary (GEN) Wojtek (GEN) today not saw father "Mary's father did not see Wojtek today." (or “Wojtek's father did not see Mary today.") 


\subsection{Post-verbal finite clauses}

In 9. the identification requirement is restricted to NP arguments. It is possible that it should be extended to apply to clauses. Just as with NPs, clauses can be arguments with specific syntactic and semantic functions. In the parsing process these have to be read off the utterance from the formal properties of the clause.

Consider:

87.a. [That he ate so much at dinner] meant [that he was hungry.]

b. [That he has eaten so much at dinner] caused [that he has indigestion now.]

The subject and object clauses should be uniquely identified for the same reason as the NPs in 88 .

88. [His gluttony at dinner] caused [his present indigestion].

In fact, the sentences in 87. meet USIR, as both embedded clauses occupy the positions "licensed" by the positional template in 72. (PDT). The subject clause is clause initial (DF 1)and the object clause is clause final(DF $5)$.

Note that the "doubling" of sentence final clauses in English by extraposition is not allowed.

89.a. That he ate so much for dinner does not mean that he was very hungry.

b. *It does not mean [that he was very hungry][ that he ate so much for dinner].

Emonds (1970) noticed similar restriction on base derived VP internal clauses.

90. ${ }^{*}$ He explained to his boss [that he was absent] [that he was sick].

Polish seems to share these restrictions.

91. *Oznacza, [że jest głodny], [że tak dużo je]. means that is hungry that so much eats

92. *Wythumaczyl, [że byt nieobecny], [że byt chory]. explained that was absent that was ill

The reason for the similarity is the fact that, unlike with NPs, the syntactic function of a clause is marked in the same way in both languages, i.e. by their position. The general problem with $\mathrm{CP}-\mathrm{CP}$ sequences in both languages 
is thus the same as with the NP - NP sequences in English, or to some extent as with two genitive NPs following a noun head as discussed earlier.

Note that the Polish sentences above are perfectly normal if embedded sentences are accompanied by case carrying expletive pronouns that serve as their function markers and "unique identifiers".

93. Przeczy [temu, [że jest chory]], [to, [że przyszedt na $\begin{array}{llll}N P & C P & N P & C P \\ \end{array}$ It-contradicts it (INSTR) that is ill it (NOM) that came to party "That he came to the party contradicts that he was ill."

94.Wyttumaczyt [to,[że byt nieobecny,]] [tym, [że byt chory]]. $N P C P \quad N P \quad C P$

He-explained it (ACC) that he was absent it (INSTR) that he was

"He explained his absence with his illness."

The function of the "identifier" can also be fulfilled, in both languages, by CP introducing elements like complementizers or fronted wh-words. 95. and 96.are perfectly well formed.

95. He said [that Mary is ill] [when she did not show up].

96. I will say [ that John is a genius] [if/when he passes this test].

Note, finally, that 97. does not violate USIR since the adjacent that clauses are in different theta domains.

97. John said [that Mary believes [that Bill is very rich.]]

\section{Summary and conclusions}

It is evident that for human language to be an efficient tool of communication it must meet two conditions:

a) The distinctions in meaning must be reflected in distinctions in form.

b) The exact nature of the formal distinctions must be adjusted to the specific cognitive capabilities and resources of the human speaker/hearer that he could use to process the language expressions. The adjustment should be optimal to assure accurate and fast encoding and decoding of messages.

The present paper attempts to formulate some conditions for such an adjustment. The conditions are claimed to have the status of Parser's Requirement on Structure (PROS) and are intended as a fragment of a 
theory of "language diacrisis", the set of universal restrictions on possible ways in which language units (sounds, words, phrases) and relations can be formally differentiated from one another.

A fundamental principle of diacrisisis is the Unique Structural Identification Requirement (USIR). It requires that all argument (nonadjunct) NPs (perhaps CPs as well) are uniquely identified (definable) in terms of the structural-grammatical (non-lexical) properties (diacritic features) at the Surface Level of structure, roughly equivalent to Phonological Representation of the GB theory but enriched with some elements (cf. remarks in fn.7). The manner of identification depends on the grammatical resources available within the given language type. The inflectional languages like Polish use morphological case, the noninflectional, like English, use word order position (hence the term "positional languages" used here).

Identification through position is claimed to be restricted to adjacency to an element taken from a limited set of the perceptually prominent structural "anchors" or "pointers"- theta- marking heads of phrases and some phrase boundaries. These restrictions are conjectured to be behind several syntactic properties of English such as:

1) Transitive verb must be adjacent to its object (no interpolated adverbs).

98. *John likes very much Mary

2) Only one topic or wh-phrase can appear before the subject 99. *Mary the book John gave.

100. *What to whom did John give?

101. *Whom this book did John give?

3) No argument NPs can appear between the subject and the verb 102. *John them likes.

4) Only one NP can be affected by Right Node Raisings. 103. *I gave and John sold Mary a ring.

5) Only one finite "that" clause can follow the verb in: 104. *It means that Mary is happy that she is smiling.

6) Nouns can take only one "of" PP complement. 105. * The deprivation of the children of the money.

The examples in 98.-105 are cases where grammar responded to what we assume to be a functional pressure from the processor. It is of secondary importance what exactly the formal-grammatical nature of this response is. In the case of 98. it could be a selection of the [+adjacency] 
value of a parameter in an abstract Case theory. As for 99.-101., a classical account (Lasnik and Saito 1984) assumes a universal restriction of a single SPEC/COMP position coupled with a language specific prohibition on adjunction to IP. 102. is the consequence of English being a VO language in the base (specific value of the head parameter)and the lack of overt object fronting. The account for 103. may involve a restriction on rightward "across-the-board" adjunction to IP.104. and 105.could violate some surface structure filter.

Several different grammatical accounts for the ill- formedness of 101.-108. could be and have been proposed in syntactic literature. ${ }^{16}$ While the exact solutions may vary and change, it is clear that they involve several independent grammatical rules or parameters. In other words, on purely formal-grammatical grounds there seems to be no unified explanation for this cluster of grammatical properties of English. The functional account proposed here offers such unification.

It has been claimed that the grammatical properties that 98.-105. exemplify are linked, via the principles of "diacrisis", to the noninflectional status of English. It has also been shown that in Polish, a typically inflectional language, the grammatical counterparts of 98.-105. are all well-formed, as predicted.

If the analysis is correct, it demonstrates that the presence or absence of inflections is an important grammatical parameter with several non-obvious syntactic consequences. The correlation of properties shown above seems to define two syntactic types: positional and inflectional. As the explanation for the property clustering is functional (has among its premises principles related to the communicative function of a language), we have a case of a "functional typology".

There are some obvious ways in which the accuracy of these conclusions, based on the comparison of two languages, could be further tested. Other rigid and free word order languages should be analyzed to check whether they share the same configuration of grammatical facts as those observed in English and Polish. Independently, one could examine historical evidence to see whether the loss of inflections attested in many

${ }^{16}$ Consider, for example, the minimalist version of the abstract Case theory, where Objective/Accusative Case is checked in the position of a specifier of a functional category in the extended domain of the verb (Chomsky1991).It is clear that within this approach a simple GB style parametric account for 103. suggested above will have to be replaced with some other analysis. One minimalist account for the verb-object adjacency can be found in Koizumi 1995, where object moves overtly out of VP to Spec/AgrO across the VP adverbs, which are all assumed to be adjoined to VP. The moved object finds itself in the position adjacent to $\mathrm{V}$ that had also been raised from VP to the position of the head of a higher phrase with AgrOP as a complement. It might then be that the relevant parameter has to do with the ability of VP adverbs to adjoin to AgrOP in Polish but not English. One might also assume that both languages undergo object raising to AgrOP, with adverb interpolation in Polish being the result of subsequent scrambling. 
Tadeusz Zabrocki: Syntactic diacrisis in arigid and a free word order language

languages and the consequent rigidity of the word order could be linked to the emergence of syntactic properties that have been claimed here to be related to the positional character of a language. These are clearly defined questions which could guide what seems to be an interesting research program. 


\section{REFERENCES}

Bever, T.G., and Langendoen (1971) A dynamic model of the evolution of language. Linguistic Inquiry : 433-461

Bever,T,G.,McElree,B (1988) Empty categories access their antecedents during comprehension. Linguistic Inquiry . 19:35-43.

Berwick, R.C., and Weinberg, A. (1984) The grammatical basis of Linguistic Performance. MIT Press.

Biber,D.,Johansson,S.,Leech,G.,Conrad,S.,Finegan,E.(1999) Longman Grammar of Spoken and Written English. Longman.

Bolhuis, J.J., Tattersall, I., Chomsky, N., Berwick RC (2014) How Could Language Have Evolved? PLoS Biol 12(8): e1001934. doi:10.1371/journal.pbio.1001934)

Chomsky, N. (1981) Lectures on Government and Binding. Foris

Chomsky, N. (1991). Some notes on the economy of derivation and representation. In Robert Freidin, (ed.) Principles and Parameters in Comparative Grammar. MIT Press: 417-454.

Chomsky, N. (2005) Three factors in language design. Linguistic Inquiry, Vol. 36, No. 1: 1-22.

Chomsky,N. (2007)http://techtv.mit.edu/videos/16291-the-biology-ofthe-language-faculty-its-perfection-past-and-future).

Chomsky, N., and Lasnik, H. (1971) Filters and control. Linguistic Inquiry 8: 425-504.

Croft, W. (1995) Autonomy and functionalist linguistics. Language 71: 490-532.

Dryer, M.S. 2013 Order of Subject, Object and Verb. In Dryer M.S., Matthew S. ,Haspelmath, M. (eds.) The World Atlas of Language Structures Online. Leipzig: Max Planck Institute for Evolutionary Anthropology.

(Available online at http://wals.info, Accessed on 2016-o6-15.).

Emonds, J. (1976) A Transformational Approach to English Syntax. Academic Press

Featherston,S. (2001) Empty categories in sentence processing. John Benjamins

Fodor, J.D. (1978) Parsing strategies and constraints on transformations. Linguistic Inquiry 9: 427-473.

Fodor,J.D. (1983) Constraints on gaps: is the parser a significant influence? Linguistics 21: 9-34.

Fodor, J.D. (1984) Constraints on gaps: is the parser a significant influence. In Butterworth, B., Comrie, B. and Dahl, O. (eds.). 
Tadeusz Zabrocki: Syntactic diacrisis in arigid and a free word order language

Explanation for Language Universals, Mouton: 9-34.

Grice, P. (1975) Logic and conversation. In Cole, P., Morgan, J. Syntax and semantics. 3: Speech acts. Academic Press. pp. 41-58.

Grimshaw, J. (1991). Extended projection. Unpublished manuscript, Brandeis University,. (also appeared in J. Grimshaw (2005), Words and Structure, Stanford: CSLI).

Grucza, F. (1970) Sprachliche Diakrise im Bereich der Ausdrucksebenen des Deutschen. Beitrąge zur allgemeinen Sprachtheorie. Prace Komisji Językoznawczej PTPN, zeszyt 2, tom IV.

Grucza, F, (2010) Stratyfikacyjny model budowy i diakryzy języków ludzkich. Euro-edukacja

Hawkins, J.A. (1983) Word Order Universals, Academic Press.

Hawkins, J.A. (1994) A performance Theory of Order and Constituency, Cambridge University Press.

Hawkins, J.A. (2004) Efficiency and Complexity in Grammars, Oxford University Press

Kayne, R. S. (1994). The Antisymmetry of Syntax.. MIT Press.

Kayne, R. S. (2015) Antisymmetry and Morphology. Prefixes and Suffixes. https://wp.nyu.edu/roots4/wp-

content/uploads/sites/1403/2015/o7/kayne.pdf

Koizumi, M. (1995) Phrase Structure in Minimalist Syntax. unpublished MIT PhD Thesis

Kuno, S., Robinson, J. (1972) Multiple WH-Questions. Linguistic Inquiry 3: $463-487$

Larson, R. K. (1988). On the double object construction. Linguistic Inquiry 19 (3): 335-391.

Lasnik, H. and M. Saito. 1984. On the nature of proper government. Linguistic Inquiry 15:235-289

Leech, G. (1983).Principles of Pragmatics. 9th edition. Longman

Müller, G. (2000) , Free word order, morphological case, and sympathy theory. http://home.uni-leipzig.de/muellerg/mu1.pdf

Newman, A.J., Supalla,T., Hauser,P., Newport,E.L. ,Bavelier,D. (2010) Dissociating neural subsystems for grammar by contrasting word order and inflection. Proceedings of the National Academy of Science.vol. 107 no. 16: 7539-7544

Newmeyer, F.J. (1998) Language Form and Language Function, MIT Press.

Stowe,L. (1986) Parsing wh-constructions: Evidence for on-line gap location. Language and Cognitive Processes I: 227-245.

Zabrocki, L. (1962) Phon Phonem und distinctives Morphem, Biuletyn 
Investigationes Linguisticae, vol. XXXIV

Fonograficzny. V,: 59-87. 